\title{
Correction to: Efficient Use of UAVs for Public Safety in Disaster and Crisis Management
}

\author{
Noureddine Mehallegue ${ }^{1,2} \cdot$ Mourad Djellab $^{3} \cdot$ Khaled Loukhaoukha $^{1,4}$ \\ Published online: 3 September 2020 \\ ๑) Springer Science+Business Media, LLC, part of Springer Nature 2020
}

\section{Corretion to:Wireless Personal Communications https://doi.org/10.1007/s11277-020-07719-y}

The names of the second and third authors in the initial online publication were not correctly typeset. The original article has been corrected.

Publisher's Note Springer Nature remains neutral with regard to jurisdictional claims in published maps and institutional affiliations.

The original article can be found online at https://doi.org/10.1007/s11277-020-07719-y.

Noureddine Mehallegue

nmehallegue01@qub.ac.uk

1 Research and Development Centre, Algiers, Algeria

2 The Institute of Electronics, Communications and Information Technology, Queen's University of Belfast, Belfast, UK

3 National Institute of Forensic Science and Criminology, Algiers, Algeria

4 Department of Electrical and Computer Engineering, Laval University, Quebec, Canada 